\title{
Günther Anders, fenomenólogo e agitador
}

Felipe Catalani ${ }^{1}$

Os dois textos aqui traduzidos fazem parte do espólio de Günther Anders e só recentemente foram publicados na Alemanha, em um volume que reúne seus escritos de antropologia filosófica, a maioria deles sendo considerados "de juventude"2. Desse volume, os textos mais célebres decorrem de uma conferência proferida em 1930 na Kant-Gesellschaft e cujo título dá nome ao livro: Die Weltfremdheit des Menschen - o que poderia ser traduzido, de modo não literal, como "O homem é estranho ao mundo". O texto original de Anders, que na época ainda se chamava Günther Stern, foi perdido. Restou somente sua tradução francesa publicada alguns anos mais tarde na revista Recherches philosophiques, então editada por Alexander Koyré, responsável pela recepção da produção filosófica alemã mais recente na França. A conferência de Anders (Stern) foi dividida em dois textos, Pathologie de la liberté: Essai sur la non-identification e Une interpretation de l'aposteriori, tendo sido o segundo traduzido por Emmanuel Lévinas.

É desconhecida a data dos textos "Sobre o olho" e "Homo animal jacens". O que se sabe sobre eles é que fazem parte de um convoluto de 209 folhas, que continha o título "O terror suave e outros estudos sobre o conformismo" (Der sanfte Terror und andere Konformismus-Studien): esse era o título original de A obsolescência do homem, cujo primeiro volume foi publicado em 1956, e o segundo em 1980. Esses dois artigos, portanto, já se distinguem da prosa filosófica de seus textos dos anos 1920 e 1930, e começam a assumir um caráter de ensaísmo de intervenção, embora tanto a fenomenologia quanto a antropologia filosófica, que marcaram definitivamente sua trajetória intelectual, estejam aqui bastante presentes (Anders estudou com Husserl em Freiburg, com Heidegger em Marburg e também foi assistente de Max Scheler). Entretanto, pouco se compreende o pensamento de Anders caso se caia na tentação de derivá-lo das doutrinas de seus antigos mestres. Apesar de um certo vocabulário comum (o conceito enfático de mundo, por exemplo, permanecerá até sua obra tardia), suas formulações frequentemente estão em franca oposição àqueles com quem ele havia estudado. Sua própria ideia de antropologia filosófica, por exemplo, que ele chega a chamar de uma antropologia negativa, é, ao mesmo tempo, uma crítica

1 Doutorando em Filosofia pela Universidade de São Paulo.

2 ANDERS, Günther. Die Weltfremdheit des Menschen: Schriften zur philosophischen Anthropologie. Munique: C.H. Beck, 2018. 
à analítica do Dasein de Heidegger. Se o "ser-aí" heideggeriano é sempre já um serno-mundo - enraizado, portanto (a ponto de Anders ver nele uma WurzelAnthropologie ${ }^{3}$ ) - já em Pathologie de la liberté o homem aparece como estranho ao mundo, ou, ainda, como de antemão desprovido de mundo. "Homem sem mundo" será justamente o título do livro que reúne seus ensaios sobre literatura e arte ${ }^{4}$, e podemos dizer, no limite, que essa "ausência de mundo" (um tema também em Hannah Arendt, com quem ele fora casado e manteve um diálogo de vida toda) é uma elaboração própria sobre a alienação - embora ele evite empregar o termo a torto e a direito, pois o conceito já havia se tornado excessivamente desgastado. De todo modo, lhe interessava analisar uma condição "antropológica" em processo de mutação, mas que tinha um lastro social. Não por acaso, o protótipo do homem sem mundo será o desempregado Franz Biberkopf, isto é: será no romance Berlin Alexanderplatz de Alfred Döblin que ele encontra uma "metafísica dos desempregados".

A relação de Anders com Husserl tampouco era desprovida de atritos. Em uma entrevista, ele conta, por exemplo:

No ano de 1924, ou seja, eu era um garoto de 22 anos, defendi meu doutorado com Husserl. Nos dávamos muito bem, toda semana fazíamos uma caminhada; ele era um homem velho, de má aparência, e lhe agradava quando alguém andava com ele. De modo peripatético, fazíamos juntos análises fenomenológicas e, na maioria das vezes, uma vez que inconscientemente ele havia considerado a visão como o modelo da "percepção em geral", fazíamos análises dos sentidos que ele havia negligenciado: dos sentidos não-óticos, ou seja, da audição, do olfato, e nomeadamente das sensações corporais - o que lhe desconcertava bastante, pois nessas análises tornava-se duvidosa sua diferenciação, supostamente válida e absoluta, entre "ato intencional" e "objeto intencional".

Contra Husserl, Anders frequentemente assumia certo ímpeto "materialista" (por convicção política, que ressoava na teoria), ou até, se quisermos, "pragmatista": ele mesmo conta ter lido com entusiasmo os Essays in Experimental Logic de John Dewey, que teria avançado na mesma direção pela qual ele estava interessado desde sua juventude. A tese de doutorado que ele defende sob a orientação de Husserl - ao mesmo tempo já direcionada, segundo ele, contra o orientador - intitula-se Die Rolle der Situationskategorie bei den "logischen Sätzen" (O papel da categoria de situação nas

3 SCHUBERT, Elke (Org.). Günther Anders antwortet. Interviews und Erklärungen. Berlin: Tiamat, 1987, p. 24.

4 Anders retoma, na introdução deste livro, diversos desses argumentos teóricos em torno da "ausência de mundo".

5 SCHUBERT, Op. cit., p. 26. 
"proposições lógicas"). A "situação" (que será, como se sabe, uma categoria central para Sartre) torna-se para ele um meio de levar a cabo uma pretensão própria da fenomenologia, a saber: o filosofar concreto e a direção do pensamento às coisas mesmas - zu den Sachen selbst, segundo o mote husserliano, que na França ganhará o nome de "vers le concret" (o que será difamado pelos frankfurtianos, esses sim versados em Hegel, como falso imediatismo). Anders constantemente joga as pretensões das "filosofias concretas" contra elas mesmas, acusando-as de permanecer, ainda, "abstratas" - sobretudo devido à cegueira sociológica (e antropológica) própria da filosofia. Por exemplo, um de seus artigos (escrito em inglês) intitula-se justamente "On the Pseudo-concreteness of Heidegger's Philosophy".

Essa "forma mista de filosofia juntando pragmatismo e fenomenologia" no jovem Anders, que teria aberto o caminho para uma "fenomenologia prática", não deixa de ser um caminho singular do autor para a consolidação de um materialismo próprio: o primado do teórico (isto é, da teoria do conhecimento) em Husserl dá lugar ao primado da práxis ${ }^{8}$. Nos termos de Laurent Perreau, "é reinscrevendo a fenomenologia na prática, na efetividade da situação histórica, que ela encontrará,

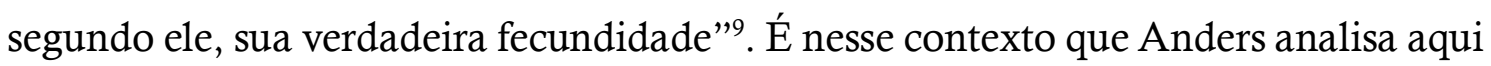
o olho, não somente em sua capacidade de perceber (de "receber"), mas também em sua capacidade de lançar, alvejar, arremessar olhares; em suma, em sua dimensão ativa. Essa passagem de um primado do conhecimento a um primado da prática se torna explícita, por exemplo, na passagem em que, mantendo o par conceitual fenomenológico clássico "intenção" e "preenchimento" (Intention e Erfüllung), ele diz:

Concretamente: ninguém é saciado pela percepção do pão, e enquanto algo somente percebido, o pão não está "presente", nem mesmo para o fenomenólogo com fome. Aquele que tem fome encontra "preenchimento" [Erfüllung] somente quando a percepção o conduziu à padaria, na qual ele pode

6 ANDERS, Günther. "On the Pseudo-concreteness of Heidegger's Philosophy". Philosophy and Phenomenological Research, vol. 8, n. 3, p. 337-371, mar. 1948.

7 PERREAU, Laurent. "Günther Anders à l'école de la phénoménologie". Tumultes, vol. 28-29, n. 1-2, 2007, p. 28.

8 A interferência do "materialismo histórico" (Anders fora leitor sobretudo do jovem Marx) em suas reflexões fenomenológicas e de antropologia filosófica é notável já em seus textos de juventude: "O materialismo histórico teve o mérito de ter reformulado o sentido específico do idealismo kantiano, isto é, a transformação da razão teórica em razão prática" (STERN, Günther. "Pathologie de la liberté: Essai sur la nonidentification". Recherches philosophiques, vol. VI, p. 22-54, 1936-1937).

9 PERREAU, Op. cit., p. 33. 
então, em sentido verdadeiro, "pegar" [nehmen] o pão, ou seja, "consumi-lo" [zu sich nehmen $]^{10}$.

Está em jogo uma dimensão "prática" da intencionalidade, em que se distingue conhecer o pão e comer o pão. A fome, como uma figura da falta (que aparecerá como "instinto" ou "necessidade" [Bedürfnis]), será também uma constante em Anders.

É certo que a investigação sobre o "lançamento" nesses dois textos não é inocente. Em "Sobre o olho", o autor aborda o olhar lançado dos amantes; em "Homo animal jacens", aparece a técnica balística e, por fim, o objeto por excelência de Anders: o drama da civilização contemporânea na época de sua autodestrutibilidade técnica. Mas a desenvoltura filosófica com a qual Anders consegue abordar os mais diversos objetos - inclusive uma coisa tão não-metafísica como a bomba atômica - não deixa de ser algo que ele aprende com seu antigo professor. Não custa lembrar que também Sartre redescobriu o mundo por meio da fenomenologia e sua "ideia fundamental", a "intencionalidade", isto é, a compreensão de que a consciência é sempre consciência de algo, portanto ela está sempre "fora", no mundo, vinculada aos objetos. Tal "descoberta" destravava a filosofia universitária francesa, então presa à metafísica e à epistemologia estritas, e entrava em jogo todo o "mundo da vida" - que no caso incluía a política, o cinema, a literatura etc. Como conta Sartre:

O enviado do Céu, para mim, foi Raymond Aron. Voltando de Berlim, ele me falava dos fenomenólogos em um bar: "esses caras", conclui ele sorrindo, "encontram o meio para filosofar sobre tudo. Eles passariam a noite a descrever fenomenologicamente a essência de uma lanterna". Fui transportado: nada me parecia mais importante que a elevação dos postes de luz à dignidade de objeto filosófico ${ }^{11}$.

É nesse ponto em que uma reflexão de caráter fenomenológico encontra um viés, por assim dizer, "teórico crítico", de compreensão do mundo presente, despreocupado em relação às "grandes e eternas questões". Sabe-se que, no procedimento fenomenológico, vai-se diretamente ao objeto e não se gasta muita prosa com referências em história da filosofia - e, de fato, é bastante raro Anders citar algum filósofo em seus textos, a não ser que ele seja diretamente o objeto da crítica. Conta ele: "Quem estudou com Husserl aprendeu quase nada de história da filosofia além de Berkeley, Hume, Descartes e Locke. Falando francamente, ele foi

10 "Homo animal jacens", p. 116.

11 Citado em: DOSSE, François. La saga des intellectuels français, 1944-1989. Paris: Gallimard, 2018, 2 vols. 
o filósofo mais iletrado em história da filosofia que já encontrei"12. Apesar do gracejo, essa suposta "ignorância" em relação à própria filosofia não é algo que, em si, Anders julga como deletério. Não passar a vida atolado nas grandes questões da história da filosofia não é um pecado filosófico, pelo contrário: interessa-lhe antes o pensamento politizado daquele que enfia a mão na massa podre do social e não se contenta com a solenidade daquilo que é supostamente elevado. "Pensadores que continuam a filosofar como se não houvesse energia nuclear nem mísseis e que tomam essa renúncia como uma ascese natural e conveniente ao filósofo - esses não podem mais ser levados a sério"13. Em outra entrevista, diz ele ainda: "Embora eu seja classificado como 'filósofo', eu me interesso pouco por filosofia. Meu interesse é pelo mundo. Assim como o interesse do astrônomo não é pela astronomia, mas pelas estrelas. Se existe algo como filosofia, e se chamam o que eu faço de filosofia ou de sei lá o quê, para mim tanto faz" ${ }^{\prime 14}$. A posição é de um polemista em mais uma de suas Ketzereien (heresias) - tal o título de outro livro seu. Mas nela, ao mesmo tempo, não deixa de ressoar a lição de seu antigo professor, com seu interesse pela Sache.

12 SCHUBERT, Op. cit., p. p. 25.

13 "Homo animal jacens", p. 120.

14 SCHUBERT, Op. cit., p. 67. 



\section{Sobre o olho [sem data]}

Günther Anders

Tradução de Felipe Catalani*

É inacreditável o quanto se tem de não saber para ser reconhecido como psicólogo sensorial [Sinnpsychologe]. Uma vez que se possa revirar bibliotecas de psicologia da percepção - aquilo que é mais importante será buscado em vão, o mais inquietante nem mesmo será mencionado. Sobretudo os fatos seguintes, estreitamente conectados, permanecem não mencionados:

O olho não só apreende ao perceber [vernimmt], como o ouvido, mas ele também designa [zeigt]. Faz sentido falar de um olho "falante", e não faz sentido falar de um "ouvido falante". O olho não só vê [sieht], mas, sempre que ele vê, ele também dirige o "olhar para fora" [aussieht]. Em outras palavras, o olho não trabalha somente como um órgão receptor, mas também como um órgão emissor. Não ocorre sem motivos a denominação de certos italianos como "jettatori"1. E com exceção dos psicólogos da percepção, todos sabem (inclusive a menina de quatorze anos, que foi fixamente fitada por um passante, e até mesmo o sapo fascinado por uma serpente) que olhares podem ser lançados.

Em outras palavras: o que permanece não mencionado é a energia do olho, o fato de que ele dispõe de força e poder. E isso significa que ele dispõe não de algo como a força de ver - isso é relativamente desimportante -, mas sim a força de arremessar. Ele pode não somente receber [empfangen], mas capturar [fangen]; não somente perceber [vernehmen], mas tomar [nehmen], segurar [festhalten], "constatar" [feststellen], acariciar e punir. Em todo caso, esse poder nunca foi investigado, apenas a capacidade de recepção foi considerada digna para os institutos. A dimensão dessa omissão pode se tornar presente mediante comparação. A saber, imaginemos que os psicólogos, ao abordarem as faculdades acústicas do ser humano, fossem culpados de omissão análoga: restringem-se portanto à investigação da receptividade, mas ignoram as capacidades de emissão. Em tal caso, estaríamos diante de um resultado

* O tradutor agradece a Anderson Gonçalves pela leitura atenta das traduções e pelas sugestões de revisão.

1 Nota do Tradutor: Literalmente: "lançadores". Na superstição popular, sobretudo no sul da Itália, os jettatori trazem má sorte, de forma análoga ao que chamamos de "mau olhado". 
assim: haveria por certo uma psicologia da audição; em compensação, não haveria uma da fala.

Ou talvez essa comparação seja distorcida? E isso porque decerto os dois sentidos se distinguem fundamentalmente? Porque à província acústica é prevista uma divisão do trabalho, e à província ótica não? Porque naquela há dois órgãos, um ativo (a boca) e um passivo (o ouvido); já nesta última há somente um único órgão, o olho, que domina de forma autocrática? Pois os desempenhos atribuídos às regiões do sentido são assimétricos?

Eu não creio. Em si mesmos, ambos os fatos - a "autocracia do olho" e a "assimetria dos sentidos" - são incontestáveis; são mesmo de uma importância tão decisiva que eu afirmaria que nenhuma filosofia dos sentidos que falhe em trazê-los à tona pode querer ser levada a sério cientificamente. Mas isso não quer dizer que esses dois fatos apresentem oposições a nossa comparação. O que é comparado não são os órgãos, mas seus desempenhos. E eles são análogos. Pois assim como aquele que ouve corresponde àquele que vê, aquele que fala corresponde àquele que observa, a quem lança olhares. $\mathrm{O}$ par de produções desempenhadas que está em questão em ambos os casos (o par "perceber" e "fazer-se-percebido", isto é, "receber" e "capturar") é, em ambos os casos, um só, o mesmo. E uma vez que os psicólogos da percepção trataram exclusivamente do perceber receptor, sua omissão permanece uma omissão.

Mas mesmo então, quando se observa o caso do "jettatore" só como um casolimite, que não tem significado filosófico, a exclusividade com a qual a psicologia sensorial até então lidou com a visão não seria justificada. Pois ainda é também incontestável que o olho não só vê [sieht], mas ele também olha [blickt]. Entendo por "olhar" certamente não só aquilo que foi investigado exaustivamente sob o título de "atenção", mas o verdadeiro commercium, no qual entra olho com olho e que se distingue, por princípio e fundamento, do mero "ver". E se distingue, por princípio e fundamento, como o amar do observar [Beobachten].

É que não vemos os olhos de nossos semelhantes do mesmo modo que vemos botões - o que é provado por nada melhor que o fato de chamarmos certos olhos (anormais) de "olhos redondos como botões", expressando com isso o fato de que esses olhos, devido a alguma deficiência, não podem ser vistos tal como os olhos realmente são vistos, tal como almejamos ver os olhos. Pois nós não apenas vemos olhos, mais que isso, nós podemos "olhar nos olhos", dentro deles.

Essa palavrinha "dentro" [hinein] mostra novamente um caráter peculiar do olhar. E embora seja certamente bastante difícil precisar o que de fato ocorre quando olhamos "dentro", descartar tais expressões simplesmente como "metáforas" seria 
pura conveniência, mesmo que a defesa contra metáforas seja normalmente justificada com rigor científico. Metáforas devem ser tomadas a sério, elas nunca são simplesmente um disparate, elas são antes indicações de problemas genuínos. Sem falar que frequentemente tais expressões absolutamente não são metáforas; elas só valem como "metáforas" para aqueles que, devido a um conceito de ciência preconcebido, pensam saber quais usos das palavras devem ser tomados como originários e não-figurativos. Em nosso caso isso significa: é questionável se devemos admitir que olhamos "dentro" de um olho em um sentido menos originário do que quando entramos "dentro" ["hinein" gelangen] de uma casa. O "dentro" ["hinein"] não possui um sentido exclusivamente espacial; e "espaço" não possui somente o sentido que ele tem na física. É inquestionável que para nós a designação poética para olhos: a saber, "janelas", possui mais verdade que a maioria dos resultados da psicologia da percepção, pois ela indica que se olha nos olhos, dentro deles $[\text { hineinblickt }]^{2}$.

Mas isso também não é suficiente. O que ocorre como "olhar dentro" não acontece como se um olho A entrasse dentro de um olho B, tal como um homem A dentro de uma casa B; de modo que, portanto, seria possível diferenciar claramente o sujeito e o objeto do processo. Os olhos, antes, mergulham uns nos outros. E certamente ao mesmo tempo. No olhar dos amantes, os olhos de ambos os parceiros são ao mesmo tempo sujeito e objeto, ao mesmo tempo buscam e são buscados, olhar e ser-olhado acontecem ao mesmo tempo, como um e mesmo processo. Somente expressões da filosofia da identidade seriam capazes de descrever o processo. Certamente pode-se até mesmo ir ao ponto de afirmar que esse commercium vai muito além de uma relação somente "visual", ele não é mais "sensorial" [sinnlich] no sentido da ciência, mas "sensual" [sinnlich] no sentido do "intercursus". O que se alcança reciprocamente em tal olhar já não é a "imagem do olho" do outro frequentemente isso nem é mais visto; mas sim "o outro", pois este, alcançável por meio do olho descerrado, está ali, aberto. E também A não é visto por B, e B por A; antes, a relação que se dá no olhar recíproco é tão íntima que os parceiros perdem audição e visão.

2 Essa característica do "para dentro" não é monopólio da visão. Pois nós podemos também "escutar a fundo" ["hineinhören" - literalmente, "escutar adentro" - possui em alemão o sentido de tornar algo íntimo por meio da escuta - N. do T.]: por exemplo, uma música ou a voz de alguém que nos fala; e é bastante certo que esse escutar a fundo se diferencia fundamentalmente daquilo que em psicologia é tratado como "escutar". Mas esses dois "dentro" ["hineins"] (o da visão e o da escuta) não são completamente iguais: pois ao olho que olha dentro do olho corresponderia um ouvido que escuta dentro do ouvido; o que seria um disparate. 
É claro que tudo isso não soa extremamente sólido, mas indigno da ciência e diletante. $\mathrm{E}$ isto somente porque a realidade mesma não é extremamente sólida, porque ela faz pouco caso das demarcações que as ciências geralmente tanto amam. Não é culpa nossa se a descrição de um ato de olhar se aproxima de uma descrição do coito. $\mathrm{O}$ olhar ocorre precisamente sob circunstâncias. Por outro lado, quando se sai do terreno oficial dos "sentidos" [Sinne], como aqui, de repente entendemos porque "sentidos" pertencem à "sensualidade" [Sinnlichkeit].

Sem dúvida: a psicologia dos sentidos precisa de uma abordagem completamente nova. Não possui nenhuma valia precipitar-se imediatamente nas produções dos sentidos, isoladamente tomadas. O que é preciso, muito mais, é elaborar uma abordagem antropológica antes, a saber, verificar as formas essenciais do trato do homem com o mundo e seu mundo-em-comum [Welt und Mitwelt]; e demonstrar essas formas nas produções dos sentidos. Exemplo - e com isso voltamos ao nosso problema inicial: deveríamos partir do fato de que o homem (diferentemente do animal, que só pode lançar-se in toto sobre algo) é um animal jacens, um animal que lança. Lançar-olhares é compreendido então como um caso subordinado, o que não significa que com isso tudo se torna compreensível. Pois também nesse caso é necessária uma investigação complementar, que deveria estabelecer como ocorre esse "lançar do olhar" e o que realmente acontece quando um olho alcança seu objeto-alvo, ou, ao contrário, quando ele é arrebatado por um olho que lança olhares. 


\section{Über das Auge [o. J. $]^{* 1}$}

Günther Anders

Unglaublich, was man alles nicht-wissen muss, um als Sinnespsychologe zu gelten. Da kann man Bibliotheken von Wahrnehmungspsychologie durchstöbern nach dem Wichtigsten wird man vergebens suchen, das Beunruhigendste noch nicht einmal erwähnt finden. Unerwähnt bleiben vor allem die folgenden, eng miteinander zusammenhängenden Tatsachen:

Dass das Auge nicht nur, wie das Ohr, vernimmt, sondern dass es auch zeigt. Dass vom «sprechenden» Auge zu reden sinnvoll, vom «sprechenden Ohr» zu reden sinnlos ist. Dass das Auge nicht nur sieht, sondern, wann immer es sieht, auch «aussieht». In anderen Worten, dass das Auge nicht nur als Empfangsorgan arbeitet, sondern auch als Sendeorgan. Die Benennung gewisser Italiener als «jettatori» ist nicht grundlos. Und außer Wahrnehmungspsychologen ist es jedermann bekannt (schon der Vierzehnjährigen, die einmal von einem Passanten fixiert worden ist, ja sogar der von einer Schlange faszinierten Kröte), dass Blicke geworfen werden können.

In anderen Worten: was unerwähnt bleibt, ist die Energie des Auges, die Tatsache, dass es über Kraft und Macht verfügt. Und das heißt nicht etwa über Sehkraft - die ist relativ unwichtig -, sondern über Wurfkraft. Dass es nicht nur empfangen, sondern fangen; nicht nur vernehmen, sondern nehmen, festhalten, «feststellen», schmeicheln und strafen kann. Untersucht wurde diese Macht jedenfalls niemals, als institutswürdig galt ausschließlich die Empfangsleistung.

Das Ausmaß dieses Versäumnisses kann man sich durch einen Vergleich vergegenwärtigen. Nämlich dadurch, dass man sich einmal vorstellt, die Psychologen hätten sich bei der Behandlung der akustischen Fähigkeiten des Menschen eines analogen Versäumnisses schuldig gemacht: sich also auf die Untersuchung der Rezeptivität beschränkt, die Sendeleistungen dagegen ignoriert.

* In: ANDERS, Günther. Die Weltfremdheit des Menschen: Schriften zur philosophischen Anthropologie. Munique: C. H. Beck, 2018, p. 310-314.

1 [Wie auch «Homo animal jacens» (S. 315-321 in diesem Band) ist «Über das Auge» Teil eines insgesamt 209 Blatt umfassenden Konvoluts mit dem Titel Der sanfte Terror und andere Konformismus Studien - so der ursprüngliche Titel der Antiquiertheit des Menschen.] 
Das Ergebnis, vor dem wir in einem solchen Fall stünden, sähe so aus: Es gäbe zwar eine Psychologie des Hörens; eine des Sprechens dagegen nicht.

Oder sollte dieser Vergleich vielleicht schief sein? Und zwar deshalb, weil die zwei Sinne sich so fundamental unterscheiden? Weil für die akustische Provinz Arbeitsteilung vorgesehen ist, für die optische keine? Weil es in jener zwei Organe gibt, ein aktives: den Mund, und ein passives: das Ohr; in dieser dagegen nur ein einziges Organ, das autokratisch herrscht, eben das Auge? Weil also die den Sinnesgebieten zugeordneten Leistungen a-symmetrisch sind?

Ich glaube nicht. An sich sind zwar diese beiden Tatsachen: die «Autokratie des Auges» und die "A-symmetrie der Sinne» unbestreitbar; ja sogar von so entscheidender Bedeutung, dass ich behaupten würde, dass keine Philosophie der Sinne, die es versäumt, diese in den Vordergrund zu rücken, beanspruchen kann, wissenschaftlich ernst genommen zu werden. Aber das besagt noch lange nicht, dass diese zwei Tatsachen Einwände gegen unseren Vergleich darstellen. Was verglichen wird, sind ja nicht die Organe, sondern deren Leistungen. Und die sind analog. Denn wie dem Hörenden der Sehende entspricht, so entspricht dem Sprechenden der Aussehende, der Blickwerfer. Das Leistungspaar, auf das es in beiden Fällen ankommt (das Paar «Vernehmen» und «Sich-vernehmbar-Machen» bzw. «Empfangen» und «Fangen») ist in beiden Fällen eines und dasselbe. Und da die Wahrnehmungspsychologen eben ausschließlich das empfangende Vernehmen des Auges behandelt haben, bleibt ihr Versäumnis ein Versäumnis.

Aber selbst dann, wenn man den Fall des «jettatore» nur als einen Grenzfall betrachtete, dem philosophische Bedeutung nicht zukäme, wäre die Ausschließlichkeit, mit der sich die bisherige Sinnespsychologie mit dem Sehen beschäftigt hat, nicht gerechtfertigt. Denn unbestreitbar bleibt auch dann noch, dass das Auge nicht nur sieht, sondern dass es blickt. Unter «Blicken» verstehe ich freilich nicht etwa nur das, was man unter dem Titel «Aufmerksamkeit» bis zum Überdruss untersucht hat, sondern das eigentliche commercium, in das Auge mit Auge tritt, und das sich vom bloßen «Sehen» ganz grundsätzlich unterscheidet. Nicht weniger grundsätzlich, als sich das Lieben vom Beobachten unterscheidet. Die Augen der Mitmenschen sehen wir nämlich nicht so, wie wir Knöpfe sehen - was durch nichts besser bewiesen wird als durch die Tatsache, dass wir gewisse (und zwar abnorme) Augen «Knopfaugen» nennen, womit wir eben zum Ausdruck bringen wollen, dass diese Augen sich auf Grund irgendeines Mangels nicht so sehen lassen, wie Augen 
eigentlich gesehen werden, und wie wir Augen zu sehen eigentlich beanspruchen. Denn Augen sehen wir nicht nur, vielmehr können wir in sie «hineinblicken»².

Mit diesem Wörtchen «hinein» ist von Neuem ein eigentümlicher Charakter des Blickes angezeigt. Und obwohl es gewiss äußert schwerfallen würde, zu präzisieren, was da eigentlich vor sich geht, wenn wir «hinein» blicken - solche Ausdrücke einfach als «Metaphern» abzutun, wäre reine Bequemlichkeit, auch wenn gewöhnlich die Abwehr von Metaphern mit wissenschaftlicher Strenge begründet wird. Metaphern müssen ernst genommen werden, einfach Unsinn sind sie niemals, vielmehr immer Indikationen echter Probleme. Ganz abgesehen davon, dass es sich bei derartigen Ausdrücken oft überhaupt nicht um Metaphern handelt; dass sie als «Metaphern» nur demjenigen gelten, der auf Grund eines vorgefassten Wissenschaftsbegriffes $\mathrm{zu}$ wissen glaubt, welche Wortverwendungen als ursprüngliche und nichtfigurative zu gelten haben. Was in unserem Falle bedeutet: Es ist uns durchaus fraglich, ob wir zugeben müssen, dass wir in einem weniger ursprünglichen Sinne in ein Auge «hinein» blicken, als wir in ein Haus «hinein» gelangen. Das «hinein» hat eben keinen ausschließlich räumlichen Sinn; bzw. «Raum» nicht allein den Sinn, den er in der Physik hat. Unfraglich aber ist es für uns, dass die poetische Bezeichnung für Augen: nämlich «Fenster», mehr Wahrheit enthält, als die meisten Ergebnisse der Wahrnehmungspsychologie, weil sie anzeigt, dass man in Augen hineinblickt.

Aber auch damit noch nicht genug. Was als «Hineinblicken» vor sich geht, das geschieht ja nicht so, dass ein Auge A in ein Auge B so hineinträte, wie ein Mann A in ein Haus B; sodass also Subjekt und Objekt des Vorgangs deutlich unterschieden werden könnten. Vielmehr tauchen die Augen ja ineinander. Und zwar zugleich. Im Blick der Liebenden sind die Augen beider Partner zugleich Subjekt und Objekt, zugleich lotend und gelotet, Sehen und Gesehenwerden finden zugleich, ja als ein und derselbe Vorgang statt. Nur Ausdrücke der Identitätsphilosophie wären wirklich instande, den Vorgang zu beschreiben. Ja man kann sogar so weit gehen zu behaupten, dass dieses commercium weit über alle nur «visuelle» Beziehung hinausgehe, dass er nicht mehr "sinnlich» im Sinne der Wissenschaft sei, sondern «sinnlich» im Sinne des «intercursus». Was in solchem Blicke gegenseitig erreicht wird, ist ja gar nicht mehr das «Bild des Auges» des Anderen - oft wird das gar nicht

2 Zwar ein Monopol des Sehens ist dieser Charakter «hinein» nicht. Denn «hineinhören» können wir ja auch: etwa in eine Musik oder in die Stimme eines zu uns Sprechenden; und dass sich dieses Hineinhören grundsätzlich von dem unterscheidet, was in der Psychologie als «Hören» behandelt wird, steht außer Frage. Aber vollkommen gleich sind sich diese beiden «hineins» (das des Sehens und das des Hörens) nicht: Denn dem ins Auge hineinblickenden Auge würde ja ein ins Ohr hineinhörendes Ohr entsprechen; was barer Unsinn wäre. 
mehr gesehen; sondern «der Andere», da dieser, durch das geöffnete Auge erreichbar, offen daliegt. Und auch nicht gesehen wird A von B, bzw. B von A; vielmehr ist eben die im gegenseitigen Blick sich vollziehende Beziehung so intim, dass den Partnern Hören und Sehen vergeht.

Natürlich klingt das alles höchst unsolide, wissenschaftsunwürdig und dilettantisch. Aber nur deshalb, weil die Wirklichkeit selbst eben höchst unsolide ist, sich nämlich nicht um die Grenzziehungen kümmert, die die Wissenschaften gewöhnlich so lieben. Unsere Schuld ist es nicht, wenn sich die Beschreibung eines Blick-Aktes einer Beschreibung des Koitus annähert. Blicken geht eben unter Umständen so vor sich. Andererseits begreift man, wenn man sich so weit aus dem offiziellen Gebiet der «Sinne» herausbegibt, wie wir es hier tun, mit einem Male, warum «Sinne» zur «Sinnlichkeit» gehören.

Keine Frage: Die Sinnespsychologie hat einen völlig neuen Ansatz nötig. Sich unvermittelt auf die als isoliert unterstellten Sinnesleistungen zu stürzen, hat keinen Wert. Was erforderlich ist, ist vielmehr, sich vorher einen anthropologischen Ansatz zu erarbeiten, nämlich die wesentlichen Umgangsformen des Menschen mit Welt und Mitwelt festzustellen; und diese Formen in den Sinnesleistungen nachzuweisen. Beispiel - und mit diesem kehren wir zu unserem Ausgangsproblem zurück: Man hätte auszugehen von der Tatsache, dass der Mensch (im Unterschied zum Tiere, das sich nur in toto auf etwas werfen kann) ein animal jacens, ein werfendes Tier ist. Das Blicke-Werfen wird dann als Unterfall begreiflich, was nicht bedeutet, dass damit alles begreiflich gemacht wäre. Denn auch dann bedarf es noch einer ergänzenden Untersuchung, die festzustellen hätte, wie dieses «Blick werfen» vor sich geht, bzw. was da eigentlich geschieht, wenn ein Auge sein Zielobjekt erreicht, oder umgekehrt von einem blickenden Auge überwältigt wird. 


\section{Homo animal jacens [sem data $]^{1}$}

Günther Anders

Tradução de Felipe Catalani

No que consiste nossa capacidade produtora [Leistung] de lançar?

Em transformarmos aquilo que está ausente em aquilo que está presente, isto é, nossa própria ausência em presença; portanto em expandir o âmbito de nossa presença.

Pois nosso mensageiro, o projétil, alcança partes do mundo (embora já antes visíveis e, portanto, "presentes" em sentido sensorial) que, em sentido pragmático, ainda eram ausentes.

Se o objeto-alvo é atingido por nosso projétil, então ele também é atingido por nós; e está agora junto de nós, portanto presente em sentido pragmático. Agora nós podemos "ir buscá-lo" [holen] e trazê-lo à presença mais direta e inequívoca. Sob certas circunstâncias podemos até mesmo "alcançá-lo" [einholen], isto é: trazê-lo a nós, sem nos mover do lugar; por exemplo, quando o projétil permaneceu, como uma vara de pesca, em conexão conosco. Sem esse "esforço de trazer" [Einbringen], os lançamentos não têm sentido. Pois cada um representa somente a primeira metade de uma ação mais ampla, que é composta pelas duas capacidades produtoras, em condução [Wegleistungen], de "alcançar" e "incorporar"; cada qual é apenas a primeira fase de uma ação-bumerangue ${ }^{2}$.

Claro que esse nexo elementar do ato não é nenhuma descoberta nova. Ele foi tratado na fenomenologia sob o título "intenção e preenchimento" [Intention und Erfüllung]. Mas não de forma satisfatória. Pois os atos que Husserl usou como modelo, e dos quais derivou essa estrutura - o par de atos representação [Vorstellung] e percepção ${ }^{3}-$, mal podem ser reconhecidos como "ter como alvo e ter [abzielende

1 [Assim como "Sobre o olho", também "Homo animal jacens" é parte do convoluto $O$ terror suave e outros estudos sobre o conformismo.] (Nota da edição alemã.)

2 Essa caracterização parece ser aplicável somente ao lançamento agressivo, já que o defensivo está claramente voltado para a "ausência". Mas isso só na aparência. Pois assim como é verdade que o inimigo, cuja presença ameaça e que agora é atingido por um lançamento, é interceptado [abgehalten], ou seja, mantido na ausência [in Abwesenheit gehalten], é igualmente verdade que esta mesma ausência assegura o raio da minha presença.

3 ["Representações" [Vorstellungen] são para Husserl todos os atos, nos quais "algo se torna para nós objetivo [gegenständlich] em um sentido mais estrito" (Edmund Husserl, 
und habende]" para além de um sentido figurado. De fato, Husserl distorceu, por restringir-se a esse modelo, a imagem de estrutura [Strukturbild] a ser desenhada. A distorção consiste em uma "deslocamento prévio" [Vorverlegung]. O que isso significa?

Isso significa que ele atribui à percepção enquanto capacidade produtora [Leistung] uma situação que só pode ser produzida por um ter efetivo e por um incorporação real, ou seja, pela situação do saciamento e da presença; com isso ele concede à percepção um mérito que não é o seu. Não é seu, pois a percepção (na medida em que a situamos de fato corretamente no contexto da atividade geral do ser vivo de modo correto) de modo algum é o "verdadeiro pegar" [wahres Nehmen]"; pois o "observar" que percebe [das wahrnehmende "Betrachten"] em geral ocorre como elemento de um "almejar" [eines "Trachtens"], pois ver é parte de uma "intenção" [Absicht] que visa conduzir ao "verdadeiro pegar", no qual a intenção se preenche. Em suma: porque também a percepção é ainda um ato que tem alvo [abzielender $A k t]$. E não no sentido mais geral da "intencionalidade" [Intentionalität] (= perceber algo $)^{5}$, mas no sentido de que ele tende a um outro ato, no qual ele se torna supérfluo. Concretamente: ninguém é saciado pela percepção do pão, e enquanto algo somente percebido, o pão não está "presente", nem mesmo para o fenomenólogo com fome. Aquele que tem fome encontra "preenchimento" [Erfüllung] somente quando a percepção o conduziu à padaria, na qual ele pode então, em sentido verdadeiro, "pegar" [nehmen] o pão, ou seja, "consumi-lo" [zu sich nehmen]. Só então o pão está "presente", só então ocorre efetivo "preenchimento". Em certo sentido, Husserl deslocou [vorverlegt] para o olho a capacidade produtora [Leistung] da boca - é isso o que eu quis dizer com a expressão "pré-deslocamento" [Vor-verlegung].

É claro que esse "deslocamento prévio" não foi acaso nem negligência que Husserl teria cometido. O que o guiou foi justamente seu interesse exclusivo na conexão estrutural dos atos teoréticos; e de fato não se pode contestar que a intenção de representação [Vorstellungs-Intention] se preenche por meio da percepção (na assim chamada "situação de evidência" [Evidenzsituation]). Tampouco é contestável que

Logische Untersuchungen. Zweiter Band. Erster Teil. Untersuchungen zur Phänomenologie und Theorie der Erkenntnis, Husserliana XIX/1, hg. von Ursula Panzer, Den Haag 1984, S. 477); a percepção, enquanto representação objetivante [objektivierende Vorstellung], é um "ato que determina significado, mas não [...] um ato que contém significado"] (Edmund Husserl, Logische Untersuchungen. Zweiter Band. Zweiter Teil. Untersuchungen zur Phänomenologie und Theorie der Erkenntnis, Husserliana XIX/2, hg. von Ursula Panzer, Den Haag 1984, p. 552).] (Nota da edição alemã.)

4 [Anders opera aqui um jogo de palavras, de difícil tradução, entre "perceber" (wahrnehmen) e "o verdadeiro pegar" (wahres Nehmen).] (Nota do tradutor.)

5 É evidente que Husserl não somente assumiu isto, como antes o enfatizou mais expressamente que qualquer um. 
para o teórico, que está em busca da verdade e não do pão, é válida a equiparação grega entre "ter" e "ver" ("eu tenho isso" = "eu vejo isso")

Só que o ser vivo, precisamente, determina-se de modo absolutamente "não grego", até mesmo completamente bárbaro: pois em vez de deixar o objeto, tal como ele está, em vez de percebê-lo como tal; isto é, em vez de pegá-lo, sem pegá-lo, o faminto esforça-se por perceber o objeto como chance; isto é, "pegá-lo" no real sentido de consumir [Zu-sich-Nehmens] e destruir. Somente por meio dessa destruição, na qual o ser (aquele que devora) incorpora o que foi pego [das Genommene], ele o torna realmente presente; somente onde ele se "enche" com o que foi pego, no sentido de refeição, ocorre real "preenchimento".

E com isso chegamos em nosso tema. No lançar. Em que medida?

É plausível que o que é presente não exija intenção nem tomada de posse. Com isso está dito que o que há para se pegar [das zu Nehmende] está por princípio e fundamento ausente. Daí que pegar requer sempre um salto. Um salto em direção ao ausente. Esse salto acontece como um lançar. Pois ele ocorre de modo que ou aquele que pega se lança sobre o ausente; ou ele lança para o ausente.

Com esta alternativa, algo decisivo é indicado.

Pois enquanto o animal permanece condenado a ficar ali onde ele fica - a não ser que ele lance a si mesmo, com toda o equipamento de seu corpo, sobre o ausente (a presa), o ser humano dispõe de um meio engenhoso que lhe permite estar efetivamente (a saber, por meio de seu efeito) em um outro lugar sem ter de deixar o lugar onde está - em suma, ele pode lançar em vez de saltar. A conhecida adivinha retórica ("Sou por acaso passarinho que pode estar em dois lugares ao mesmo tempo?"7 ) é inadequada. Pois, se é certo que o pássaro não consegue fazer isso, nós certamente o conseguimos, já que com a ajuda da pedra, da vara, do comando, da lembrança, do telefone etc. nós somos capazes de estar em dois lugares ao mesmo tempo. Esse fato poderia ser chamado de "ambipresença".

Essa "ambipresença" é um privilégio do ser humano. Pois, mesmo que, de vez em quando, ou aqui e ali, possam ocorrer indícios de lançamento pelos antropoides, somente nós fomos capazes de fazer algo do lançamento. Por isso

6 [Não é claro o que Anders poderia ter pensado exatamente com essa "equiparação". A palavra oĩ $\delta \alpha$ ("saber") no grego antigo é o aoristo de ó $\rho \alpha ́ \omega$ ("ver"), e nesse sentido o "ter" do saber seria igual ao "ter-visto" [Gesehen-Haben]. Por sua vez, o verbo para "ter" $\left({ }^{\prime} \chi \omega\right)$ no grego antigo pode significar também "compreender" no sentido intelectual do ter e captar.] (Nota da edição alemã.)

7 [Anders conhecia a frase provavelmente a partir das memórias do crítico musical Eduard Hanslick (1825-1904); cf. Eduard Hanslick, Aus meinem Leben, Berlim, 2017, p. 121 (primeira edição 1894). O carisma da bilocação é considerado pela Igreja Católica Romana como um sinal seguro de santidade.] (Nota da edição alemã.) 
podemos considerar o poder-lançar como uma característica antropológica essencial e definir o homem como um "animal jacens".

Essa definição é tanto mais justificada na medida em que ela compreende em si como caso especial também aquela capacidade produtora que serviu como differentia specifica na definição clássica do homem, o legein [dizer, falar, chamar pelo nome]. Para a forma mais originária do logos, o chamar, isso é evidente: pois chamados são ações por meio das quais tornamos agora presentes aqueles que estavam ausentes antes do chamado. Os que foram chamados respondem com "aqui" e assim confirmam a sua presença. Mas as "capacidades produtoras mais elevadas do logos" não mostram esse caráter de lançamento em menor medida. Exemplo: a dedução, o silogismo. Enquanto alguém que deduz [als Schließende], somos também "lançadores" na medida em que temos por alvo [abzielen] algo ausente (a saber, algo não sensorialmente presente) e efetivamente tomamos controle desse ausente, sem que precisemos nos aproximar diretamente do estado de coisas ausente (o que frequentemente não conseguimos fazer). Mas uma vez que o estado de coisas é deduzido [erschlossen] então ele está também descerrado [aufgeschlossen], isto é: sabido. Podemos então utilizá-lo em nosso cálculo, dispor dele - em suma, então nós o temos, e, a saber, de tal modo que nós podemos, no sentido de poder, observá-lo como "presente".

Nós vimos: a capacidade produtora de lançar consiste em construir a ponte sobre o fosso entre o horizonte sensorial e o horizonte pragmático, isto é, em nivelar o desnível [Gefälle $]^{8}$. Baseiam-se nessa capacidade produtora todas as armas que prolongam nosso corpo, a saber, todas as armas de lançamento [Wurfwaffen].

De fato, desde os primeiros dias da humanidade até nossas atuais barracas de tiro ao alvo, nossos jogos de arremesso [Wurfspiele] gozaram de tal popularidade pois nos dão a poderosa diversão [Machtspaß] de alcançar mais longe do que nós realmente alcançamos, ser maior do que nós realmente somos, e aproveitar a chance de permanecer em um lugar e em outro exercer nosso poder, embora permaneçamos onde estamos, na bem protegida etapa A.

No correr das últimas décadas, o lançar, isto é, a técnica balística, desenvolveu-se tão rapidamente que lançamentos alcançam temporariamente mais longe que o olhar. Distintamente da situação fundamental, na qual o horizonte sensorial é maior que o pragmático, o raio alcançado pelo horizonte pragmático se

8 Cf. Günther Anders, Die Antiquiertheit des Menschen [Bd. I: Über die Seele im Zeitalter der zweiten industriellen Revolution, München, 1956], p. 16 e 267 ff. [= p. 29, 296-300 da quarta edição revista de 2018]. 
tornou agora, por vezes, maior que o do horizonte sensorial, ou seja, não pode ser alcançado pelos sentidos. Já na Primeira Guerra Mundial houve bombardeios de cidades (por exemplo, de Paris) que os atiradores não conseguiam mais observar.

Rapidamente providenciamos a nivelação dessa diferença. Pois os horizontes que escancaramos com a ajuda do rádio e da televisão tornaram-se tão enormemente amplos, que logo nos vimos compelidos a novamente alcançá-los pragmaticamente. Isso foi realizado [geleistet] com o auxílio dos foguetes intercontinentais. Em certo sentido, podemos ver em sua invenção a repetição da invenção do primeiro arremesso de pedra. Pois, assim como o primeiro estilingue, agora também inventamos um meio que justamente nos permite dispor poderosa e sensorialmente de um raio [Umkreis] igualmente grande - embora seja preciso compreender sob nosso "raio sensorial", a partir de agora, o horizonte do rádio e da televisão. Novamente nós "alcançamos a nós mesmos". Só que infelizmente desta vez temos que acrescentar: infelizmente.

É preciso ter claras essas ideias básicas se quisermos compreender o caráter revolucionário daquilo que representam os corpos celestes artificiais arremessados no espaço. O que aconteceu?

Lançamos algo que jamais havíamos lançado antes. Pois nós não lançamos algo que havia sido visado [Anvisiertes] antes $^{9}$ (como o sempre fizeram aqueles que alvejam [Zielende]), pelo contrário, nós lançamos algo para, com seu auxílio, visar [anvisieren] algo. - Ou dito de outro modo: nós não "lançamos o olhar em algo", como se diz em uma metáfora justificada, mas antes nós lançamos o próprio olho como um projétil, para que ele, por sua vez, "lance um olhar". Os sputniks que traçam seu caminho veem o que nós mesmos não vemos ou registramos. Mesmo assim, permanecemos os que veem e registram [Sehende und Registrierende]: pois agora nós vemos com auxílio dos "olhos lançados", e registramos, agora por meio dos aparelhos de registro que ficaram aqui embaixo, e que acolhem [aufnehmen] aqui o que os "olhos" distantes registraram e então enviam de volta, por sua vez, como uma mensagem. Pois nós lançamos às alturas, por assim dizer, também a nossa boca.

Partimos do fato de que nosso olho sempre tem como alvo [abzielt] alcançar o distante e o ausente. E não pode ser contestado que a função dos sentidos consiste somente em tornar presente o ausente. A expressão "lançar o olhar em algo" sempre foi mais que uma metáfora. Mas agora nós demos um passo a mais. Enquanto antes, até mesmo então, lançávamos um olhar [Blick] quando olhávamos por um telescópio, agora lançamos na distância aquilo que olha [das Blickende]: o olho - de modo que

9 Escrito antes da realização das viagens à lua. 
agora este, por sua vez, lança olhares a partir dos pontos distantes alcançados - lança de volta para nós aquilo que foi olhado [das Erblickte].

O estilo de nossa existência futura e aquilo que para essa existência valerá como "mundo" não foi antecipado por nós, os que filosofam, mas por autores anônimos e vulgares. A determinação do futuro não encontrara sua formulação prévia em sólidas interpretações acadêmicas, mas em volumes de science fiction, considerados "amazing" e "astounding", impressos em papel de má qualidade. Não é exatamente um título de honra para nós filósofos o fato de aparecerem agora como adivinhações absolutamente verdadeiras as quimeras apressadamente impressas nesses livros de dez centavos, essas aventuras cósmicas estapafúrdias de arrepiar os cabelos. Dos modestos entre nós que se negam a ser incomodados com tal literatura, ou que presunçosamente afirmam não ser tarefa da filosofia manter-se tão atualizado ou perseguir aquilo que é tão concreto, deles não se deve acreditar em nada que dizem. Nós filósofos nos envolvemos completamente com o concreto e o histórico. $\mathrm{E}$ os aspectos peculiares de nossa vida, que a atual filosofia da existência [Daseinsphilosophie] leva em conta, demonstram suficientemente que nós não nos contentamos com estruturas gerais. Só que em geral perseguimos precisamente o concreto de ontem, detemo-nos refletida e posteriormente [nach-denken] sobre o caráter particular daquilo que foi [des Gewesenen]; em vez de estarmos junto do que se passa [aufdem Laufenden], estamos sempre naquilo que já está passado [aufdem bereits Abgelaufenen]. É incompreensível que uma atitude tão modesta deva pertencer à imagem do filósofo. Se as corujas do crepúsculo de hoje, que voando para trás chirriam no dia finado e o anunciam como sendo o dia de hoje ou mesmo o de amanhã - se elas evocam a coruja de Minerva de Hegel, então elas o fazem incorretamente, pois apesar de ela ter alçado voo somente com o início do crepúsculo, ainda assim ela voou em direção ao alvorecer. O enorme papel que o utópico teve na história da filosofia pode hoje menos que nunca ser tergiversado. Pois o utópico encontrou hoje os seus topous [lugar, local]: a saber, nas pranchetas dos engenheiros. E o fantástico ganhou figura, a saber, nos pavilhões industriais. Em outras palavras: o inaudito se realiza, ele se tornou um fator da realidade. E não pode ser contestado que a realidade é objeto do filosofar. Pensadores que deixam a formulação e o ato de dar forma [Formung] dessa realidade aos engenheiros e políticos, a essa equipe que, com cega providência, toma de assalto o futuro ou a ausência dele; pensadores que continuam a filosofar como se não houvesse energia nuclear nem mísseis e que tomam essa renúncia como uma ascese natural e conveniente ao filósofo - esses não podem mais ser levados a sério. Quem hoje ignora o utópico, ignora a realidade, e carece assim daquele mínimo de realismo sem o qual ninguém pode reivindicar o nome de "filósofo". 


\section{Homo animal jacens [o. J. $]^{* 1}$}

Günther Anders

Worin besteht unsere Leistung des Werfens?

Darin, dass wir Abwesendes in Anwesendes, bzw. unsere eigene Abwesenheit in Anwesenheit verwandeln; also darin, dass wir den Bereich unserer Anwesenheit erweitern.

Denn unser Bote: das Projektil, erreicht Weltstücke, die (obwohl schon vorher sichtbar, im sensorischen Sinne also «anwesend») im pragmatischen Sinne noch abwesend gewesen waren.

Ist aber der Zielgegenstand von unserem Projektil getroffen, dann ist er auch von uns getroffen; und ist nun bei uns, also anwesend im pragmatischen Sinne. Nunmehr können wir ihn «holen» und zur direktesten und nicht mehr überbietbaren Anwesenheit bringen. Unter Umständen können wir ihn sogar «einholen», d. h.: ihn zu uns bringen, ohne uns selbst dabei von der Stelle zu rühren; z. B. dann, wenn das Projektil angelartig mit uns in Verbindung geblieben ist. Ohne solches «Einbringen» bleiben Würfe sinnlos. Denn im Grunde stellt jeder nur die erste Handlungshälfte einer breiteren Handlung dar, einer Handlung, die sich aus den zwei Wegleistungen «ausgreifen» und «einverleiben» zusammensetzt; jeder ist nur die erste Phase einer Bumerang-Aktion ${ }^{2}$.

Natürlich ist dieser elementare Akt-Zusammenhang keine Neuentdeckung. In der Phänomenologie hat er unter dem Titel: «Intention und Erfüllung» seine Behandlung gefunden. Aber doch keine zufriedenstellende. Denn die Akte, die Husserl als Modell benutzte und von denen er diese Struktur ablas: das Aktpaar Vorstellung und Wahrnehmung ${ }^{3}$, können kaum in einem mehr als figürlichen Sinne

* In: ANDERS, Günther. Die Weltfremdheit des Menschen: Schriften zur philosophischen Anthropologie. Munique: C. H. Beck, 2018, p. 315-321.

1 [Wie «Über das Auge» (S. 310-314 in diesem Band) ist auch «Homo animal jacens» Teil des Konvoluts Der sanfte Terror und andere Konformismus-Studien (siehe Anm. 1 zu «Über das Auge», S. 430 f.).]

2 Diese Schilderung scheint allein auf den aggressiven Wurf anwendbar, da der defensive ja offensichtlich auf «Abwesenheit» aus ist. Aber das scheint nur so. Denn so wahr es ist, dass der Feind, dessen Anwesenheit droht und der nun von einem Wurf erreicht ist, abgehalten, also in Abwesenheit gehalten wird, so wahr ist es andererseits, dass gerade diese Abwesenheit den Umkreis meiner Anwesenheit sicherstellt.

3 [«Vorstellungen» sind bei Husserl alle Akte, in denen «uns etwas in einem gewissen engeren Sinne gegenständlich wird» (Edmund Husserl, Logische Untersuchungen. Zweiter 
als «abzielende und habende» zugestanden werden. In der Tat hat Husserl durch seine Beschrän kung auf dieses Modell das Strukturbild, das es zu zeichnen gilt, verzerrt. Die Verzerrung besteht in einer «Vorverlegung». Was heißt das?

Dass er eine Situation, die erst durch effektives Haben und wirkliches Einverleiben hergestellt wird, nämlich die Situation der Stillung und der Anwesenheit, bereits der Wahrnehmung als Leistung zuspricht; dass er dieser damit ein Verdienst einräumt, das gar nicht das ihre ist. Es ist deshalb nicht ihres, weil die Wahrnehmung (sofern man diese im Zusammenhang der Gesamtaktivität des lebendigen Wesens wirklich richtig platziert) gar nicht das «wahre Nehmen» darstellt; weil sich das wahrnehmende «Betrachten» zumeist als Element eines «Trachtens» abspielt, weil Sehen das Stück einer "Absicht» ist, die darauf aus ist, zum «wahren Nehmen», in dem die Absicht sich erfüllt, erst hinzuleiten. Kurz: weil auch die Wahrnehmung noch ein abzielender Akt ist. Und das nicht nur im generellen Sinne der «Intentionalität» (= etwas wahrnehmen) ${ }^{4}$, sondern in dem Sinne, dass er auf einen anderen Akt, in dem er sich überflüssig macht, hintendiert. - Konkret: Durch die Wahrnehmung des Brotes wird niemand gestillt, und als nur wahrgenommenes ist das Brot nicht «anwesend», auch nicht für den hungrigen Phänomenologen. «Erfüllung » findet der Hungrige vielmehr erst dann, wenn ihn die Wahrnehmung zur Bäckerei geleitet hat, in der er das Brot nun im wahren Sinne «nehmen», nämlich «zu sich nehmen» kann. Nun erst ist das Brot «anwesend», nun erst findet wirkliche «Erfüllung» statt. In gewissem Sinne hat Husserl die Leistung des Mundes bereits ins Auge vorverlegt - und das ist es, was ich mit dem Ausdruck «Vor-verlegung» gemeint hatte.

Natürlich war diese «Vorverlegung» weder ein Zufall, noch ein Versehen, das Husserl unterlaufen wäre. Was ihn geleitet hat, war eben sein ausschließliches Interesse am Strukturzusammenhange theoretischer Akte; und dass sich durch die Wahrnehmung (in der sog. «Evidenzsituation») die Vorstellungs-Intention erfüllt, das ist in der Tat nicht bestreitbar. Und ebenso wenig, dass für den Theoretiker, der auf Wahrheit, nicht auf Brot aus ist, die griechische Gleichung von «Haben» und «Sehen» gilt («Ich hab's» = «Ich seh's»)

Band. Erster Teil. Untersuchungen zur Phänomenologie und Theorie der Erkenntnis, Husserliana XIX/1, hg. von Ursula Panzer, Den Haag 1984, S. 477); die Wahrnehmung ist als objektivierende Vorstellung ein «Bedeutung bestimmender, aber nicht [...] Bedeutung enthaltender Akt» (Edmund Husserl, Logische Untersuchungen. Zweiter Band. Zweiter Teil. Untersuchungen zur Phänomenologie und Theorie der Erkenntnis, Husserliana XIX/2, hg. von Ursula Panzer, Den Haag 1984, S. 552).]

4 Das hat Husserl natürlich nicht nur zugegeben, vielmehr ausdrücklicher als jeder andere betont.

5 [Es ist nicht klar, an was genau Anders bei dieser «Gleichsetzung» gedacht haben könnte. Das altgriechische oĩ $\alpha \alpha$ («wissen») ist der Aorist von ó $\rho \alpha ́ \omega$ («sehen»), und in diesem 
Nur bestimmt sich eben das lebendige Wesen ganz «ungriechisch», sogar völlig barbarisch: Denn statt den Gegenstand zu belassen, wie und was er ist, statt ihn als solchen wahrzunehmen, und d. h.: statt ihn zu nehmen, ohne ihn zu nehmen, trachtet der Hungernde danach, den Gegenstand als Chance wahrzunehmen, d. h.: ihn im wirklichen Sinne des Zu-sich-Nehmens und Zerstörens zu «nehmen». Erst durch diese Zerstörung, in der das (fressende) Wesen das Genommene sich selbst einverleibt, macht er es wirklich anwesend; erst wo er sich mit dem Genommenen im Mahlzeitssinne «füllt», findet wirkliche «Erfüllung» statt.

Und damit sind wir bei unserem Thema. Beim Werfen. Inwiefern?

Dass Anwesendes weder Intention noch Besitznahme erfordert, das ist plausibel. Damit ist gesagt, dass das zu Nehmende grundsätzlich abwesend ist. Daher erfordert Nehmen stets einen Sprung. Einen Sprung zum Abwesenden hin. Dieser Sprung geschieht als Werfen. Denn es geht entweder so vor sich, dass sich der Nehmende auf das Abwesende wirft; oder so, dass er nach dem Abwesenden wirft.

Mit dieser Alternative ist etwas Entscheidendes angezeigt.

Während nämlich das Tier dazu verurteilt bleibt, sich dort aufzuhalten, wo es sich aufhält - es sei denn, es wirft sich selbst, in der vollen Montur seines Leibes, auf das Abwesende (die Beute), verfügt der Mensch über ein ingeniöses Mittel, das ihn instand setzt, effektiv (nämlich durch seinen Effekt) an anderen Orten anwesend zu sein, ohne doch den Ort, an dem er sich aufhält, verlassen zu müssen - kurz: er kann werfen, statt zu springen. Die bekannte rhetorische Scherzfrage: «Bin ich ein Vogel, dass ich an zwei Orten zugleich sein kann?» ${ }^{6}$ ist schief. Denn so gewiss der Vogel das nicht kann, so gewiss können wir das, da wir mit Hilfe des Steins, der Angel, des Befehls, der Erinnerung, des Telephons etc. fähig sind, uns an zwei Orten gleichzeitig aufzuhalten. Man könnte diese Tatsache «Ambipräsenz» nennen.

Diese «Ambipräsenz» ist ein Vorrecht des Menschen. Denn selbst wenn dann und wann oder hier und da bei Anthropoiden Wurfandeutungen vorkommen mögen, aus dem Wurf etwas zu machen, das haben allein wir vermocht. Darum dürfen wir das Werfenkönnen als ein anthropologisches Wesensmerkmal betrachten und den Menschen als «animal jacens» definieren.

Sinne wäre das «Haben» von Wissen gleich dem «Gesehen-Haben». Das Verb für «haben» (" $\chi \chi \omega)$ wiederum kann im Altgriechischen auch «verstehen» im Sinne des geistigen Habens und Erfassens bedeuten.]

6 [Anders kannte die Sentenz vermutlich aus den Erinnerungen des Musikkritikers Eduard Hanslick (1825-1904); vgl. Eduard Hanslick, Aus meinem Leben, Berlin 2017, S. 121 (Erstdruck 1894). Das Charisma der Bilokation gilt der römisch-katholischen Kirche als sicheres Zeichen der Heiligkeit.] 
Diese Definition ist umso berechtigter, als sie auch jene Leistung, die in der klassischen Definition des Menschen als differentia specifica gedient hatte, das legein [Sagen, Sprechen, beim Namen Rufen], als Unterfall in sich begreift. Für die ursprünglichste Form des Logos, das Rufen, liegt das ja auf der Hand: Denn Rufe sind Handlungen, durch die wir die vor dem Rufe abwesend Gewesenen nunmehr anwesend machen. Die Gerufenen antworten mit «hier» und bestätigen damit ihre Anwesenheit. Aber die «höheren Logosleistungen» zeigen diesen Wurf-Charakter nicht minder. Beispiel: das Schließen, der Syllogismus. Als Schließende sind wir nämlich insofern auch "Werfende», als wir auf etwas Abwesendes (nämlich sinnlich nicht Anwesendes) abzielen und dieses Abwesende wirklich in den Griff bekommen, ohne uns in die direkte Nachbarschaft des abwesenden Tatbestandes begeben zu müssen (was wir oft ja überhaupt nicht können). Ist aber der Tatbestand erst einmal erschlossen, dann ist er auch aufgeschlossen, d. h.: gewusst. Dann können wir ihn in unsere Kalkulation einsetzen, über ihn verfügen - kurz: dann haben wir ihn, und zwar so, dass wir ihn als im Machtsinne «anwesend» betrachten dürfen.

Wir haben gesehen: Die Leistung des Werfens besteht darin, die Kluft zwischen dem sensorischen und dem pragmatischen Horizont zu überbrücken, also das Gefälle $\mathrm{zu}$ nivellieren ${ }^{7}$. Auf dieser Leistung beruhen alle unseren Leib verlängernden, namentlich alle Wurfwaffen.

Tatsächlich haben sich unsere Wurfspiele von unseren frühesten Menschheitstagen an bis zu unseren heutigen Schießbuden deshalb einer solchen Beliebtheit erfreut, weil es uns einen immensen Machtspaß verschafft, weiter zu reichen, als wir wirklich reichen, größer zu sein, als wir wirklich sind, und die Chance zu genießen, uns irgendwo an einem Platze aufzuhalten und dort unsere Macht auszuüben, obwohl wir da bleiben, wo wir sind, in der wohlgeschützten Etappe A.

Im Laufe der letzten Jahrzehnte hat sich das Werfen, das heißt: die ballistische Technik, so rapid entwickelt, dass Würfe nun vorübergehend weiter reichen als Blicke. Im Unterschiede zur Grundsituation, in der der sinnliche Horizont größer ist als der pragmatische, ist nun der Radius des pragmatischen Horizontes zuweilen größer geworden als der des Sensorischen, kann also von den Sinnen nicht eingeholt

7 S. d. V. Die Antiquiertheit des Menschen [Bd. I: Über die Seele im Zeitalter der zweiten industriellen Revolution, München 1956], S. 16 und 267 ff. [= S. 29, 296-300 der 4., durchges. Aufl. 2018]. 
werden. Schon im Ersten Weltkriege hat es Beschießungen von Städten (z. B. von Paris) gegeben, die die Schießenden nicht mehr beobachten konnten.

Für die Nivellierung dieser Differenz haben wir freilich rasch gesorgt. Denn die Horizonte, die wir mit Hilfe von Rundfunk und Fernsehen aufgerissen haben, wurden so ungeheuer weit, dass wir uns bald dazu veranlasst sahen, diese wiederum pragmatisch einzuholen. Das wurde mit Hilfe von interkontinentalen Raketen geleistet. In gewissem Sinne dürfen wir in deren Erfindung die Wiederholung der Erfindung des ersten Steinwurfes sehen. Denn nicht anders als der erste Steinschleuderer haben auch wir nun eben ein Mittel erfunden, das uns instand setzt, achtmäßig über einen ebenso weiten Umkreis zu verfügen wie sensorisch - wobei wir unter unserem «sensorischen Umkreis» nunmehr den Horizont des Rundfunks und des Fernsehens verstehen müssen. Wiederum haben wir «uns selbst eingeholt». Nur ass wir diesmal leider hinzufügen müssen: leider.

Diese Grundgedanken muss man sich klargemacht haben, wenn man den revolutionären Charakter dessen, was die in den Weltraum hineingeschossenen künstlichen Himmelskörper darstellen, begreifen will. Was ist geschehen?

Wir haben etwas geworfen, was wir niemals zuvor geworfen hatten. Denn wir haben nicht etwas zuvor Anvisiertes beworfen ${ }^{8}$ (wie es Zielende stets getan hatten), vielmehr haben wir etwas geworfen, um mit dessen Hilfe etwas anzuvisieren. - Oder anders: Wir haben nicht, wie es in berechtigter Metaphorik heißt, «den Blick auf etwas geworfen», vielmehr haben wir das Auge selbst als Projektil benutzt, damit es seinerseits «einen Blick werfe». Die ihre Bahn ziehenden Sputniks sehen, was wir selbst nicht sehen oder registrieren. Nichtsdestoweniger sind wir Sehende und Registrierende geblieben: Denn nun sehen wir ja mit Hilfe der «geworfenen Augen», und registrieren nun vermittels jener hier unten zurückbehaltenen Registrierapparate, die dasjenige aufnehmen, was die fernen «Augen» registriert haben und nun ihrerseits als Meldung zurückschicken. Denn auch unseren Mund haben wir ja sozusagen in die Höhe geworfen.

Von der Tatsache, dass unser Auge stets darauf abzielt, das Ferne und Abwesende zu erreichen, sind wir ausgegangen. Und es kann keinen Streit darüber geben, dass die Funktion der Sinne allein darin besteht, Abwesendes anwesend zu machen. Die Redensart «seinen Blick auf etwas werfen» war stets mehr als eine Metapher gewesen. Aber nunmehr haben wir einen weiteren Schritt gemacht. Während wir früher, und selbst dann noch, wenn wir durch ein Teleskop blickten, einen Blick geworfen hatten, werfen wir nun das Blickende selbst: das Auge, in die

8 Geschrieben vor der Durchführung der Mondflüge. 
Ferne, damit dieses nun seinerseits von den erreichten Fernpunkten aus Blicke werfe, das Erblickte auf uns zurückwerfe.

Der Stil unseres morgigen Daseins und dasjenige, was für dieses Dasein als «Welt» gelten wird, war nicht von uns Philosophierenden antizipiert worden, sondern von anonymen und vulgären Autoren. Die Bestimmung der Zukunft hatte nicht in soliden akademischen Interpretationen ihre Vorformulierung gefunden, sondern in "amazing» und "astounding» heißenden, auf Makulaturpapier gedruckten Science-Fiction-Heften. Dass sich die in diesen Dime-Heften hastig heruntergedruckten Phantastereien, diese grellen und haarsträubenden kosmischen Abenteuergeschichten nunmehr als absolut wahre Wahrsagungen entpuppen, das ist für uns Philosophierende nicht gerade ein Ehrentitel. Den Genügsamen unter uns, die es von sich weisen, mit derartiger Literatur belästigt zu werden, oder die prahlend behaupten, so auf dem Laufenden zu bleiben oder so Konkretem nachzugehen, das sei nicht die Aufgabe der Philosophie, denen glaube man kein Wort. Wir Philosophierenden lassen uns durchaus auf Konkretes und Geschichtliches ein. Und die Spezialcharaktere unseres Lebens, die die heutige Daseinsphilosophie ins Auge fasst, beweisen ja hinlänglich, dass wir uns nicht mit generellen Strukturen bescheiden. Nur ist es eben gewöhnlich das Konkrete von gestern, dem wir nachgehen, gewöhnlich das Spezielle des Gewesenen, dem wir nachdenken; nur sind wir eben immer, statt auf dem Laufenden, auf dem bereits Abgelaufenen. Dass eine derart bescheidene Haltung zum Bilde des Philosophen gehören müsse, das ist nicht einzusehen. Wenn sich die Dämmereulen von heute, die, rückwärts fliegend, in den abgelebten Tag hineinkrächzen und diesen als den heutigen oder gar als den morgigen ankündigen, auf Hegels Eule der Minerva berufen, dann tun sie das zu Unrecht, denn obwohl diese ihren Flug erst mit dem Anbruch der Abenddämmerung antrat, so flog sie doch einem Morgengrauen entgegen. Die ungeheure Rolle, die das Utopische in der Geschichte der Philosophie gespielt hatte, die lasse man sich heute weniger denn je ausreden. Denn heute hat das Utopische seine topous [Plätze, Orte] ja gefunden: nämlich auf den Reißbrettern der Ingenieure. Und das Phantastische hat ja Gestalt angenommen, nämlich in den Werkhallen. In anderen Worten: Das Unerhörte realisiert sich ja, es ist ja zum Faktor der Wirklichkeit geworden. Und dass die Wirklichkeit Gegenstand des Philosophierens ist, das kann ja wohl nicht bestritten werden. Denker, die die Formulierung und Formung dieser Wirklichkeit den Ingenieuren und Politikern überlassen, diesem in blinder Vorsehung der Zukunft oder der Zukunftslosigkeit entgegenstürmenden Gespann, die ihr Philosophieren so weiterbetreiben, als gäbe es weder Atomkraft noch Raketen; und die diesen Verzicht als natürliche, dem Philosophen geziemende Askese ausgeben oder gar als 
Weisheit - die kann man nicht mehr ernst nehmen. Wer heute das Utopische ignoriert, der ignoriert die Realität, und lässt damit jenes Minimum von Realismus vermissen, ohne das niemand den Anspruch auf den Namen «Philosoph» erheben darf. 